- Modern dentistry demands continuous professional development.

- Progress files have the potential to play an important role in providing a framework for engaging dentists in the professional development of their employees and themselves.

- The whole dental team can use progress files.

\title{
Learning throughout life: can a progress file help?
}

\author{
E. S. Davenport, ${ }^{1}$ H. Fry, ${ }^{2}$ B. Pee ${ }^{3}$ and T. Woodman ${ }^{4}$
}

Modern dentistry demands continuous professional development. This paper reports part of a project to develop a lifelong learning tool known as a progress file for members of the dental team.

Aim To elucidate the views of dentists (as employers/managers) and dental therapists (as employees) on the potential use at work of a progress file. To obtain feedback from these groups on a prototype progress file for dental therapists.

Method Consultations were conducted with an opportunistic sample of 15 dentists and 32 dental therapists. Twenty eight dental therapists trialled the prototype for 6 months and 15 dentists appraised it. Opinion was obtained through interview and questionnaire, yielding largely qualitative data, which was content-analysed.

Findings Both dentists and therapists were positively disposed towards a progress file at work but considered its success conditional upon factors including input from the team leader and rewarding dentists for time spent on supporting file users. Evaluation of the prototype was mainly positive. Trial data bore out many impressions from the consultations.

Conclusion A progress file that addresses the needs of both employers and employees has potential to help all members of the dental team meet the demands of lifelong learning.

\section{INTRODUCTION}

In recent years there has been an increasing emphasis on continuing professional development (CPD) and lifelong learning in all professions, not least dentistry. Records of learning have been developed

${ }^{1 *}$ Senior Lecturer, Department of Oral Growth and Development, Barts and The London, Queen Mary's School of Medicine and Dentistry, University of London, ${ }^{2}$ Head of Centre for Educational Development, Imperial College, London, ${ }^{3}$ Research Co-ordinator, Department of Oral Growth and Development, Barts and The London, Queen Mary's School of Medicine and Dentistry, University of London, ${ }^{4}$ Research Assistant Department of Oral Growth and Development, Barts and The London, Queen Mary's School of Medicine and Dentistry, University of London *Correspondence to: Dr E. S. Davenport, Paediatric Dentistry, Barts and The London, Queen Mary's School of Medicine and Dentistry, Turner Street, London E1 2AD Email:e.s.davenport@qmul.ac.uk

\section{Refereed Paper}

Received 19.11.01; Accepted 28.11.02

doi:10.1038/sj.bdj.4810338

๑ British Dental Journal 2002; 195: 101-105 for dentists at specific stages of their careers including those entering the profession $^{1}$ and those embarking on specialist training. ${ }^{2}$ However there is no truly 'lifelong' record from training to retirement. Nor is there any such facility for professionals complementary to dentistry (PCDs).

The 1997 National Committee of Inquiry into Higher Education ${ }^{3}$ recommended the introduction, in all higher education (HE), of a 'progress file' (PF). The PF would be 'designed for people to use throughout their lives' and would include 'an official record of achievement' plus a means by which they could 'monitor, build and reflect upon their own personal development'. The development and implementation of PFs is now taking place in line with recommendations from the Quality Assurance Agency. ${ }^{4}$
The notion of a PF is in clear accord with recent initiatives within dentistry aimed at improving and upholding standards of care. It could help students prepare for independent practice upon qualification $^{5}$ and could foster habits of reflection, self-evaluation and recording of achievement amongst practitioners. ${ }^{6}$ Furthermore, as a dual role, reflective tool and staff development device, the PF could support an increasingly important aspect of dentistry, namely the need to have a motivated and responsive team.

\section{The project}

This paper reports a small part of a twoyear project to develop a PF for one member of the dental team, the dental therapist. The decision to focus on dental therapists was made against a background of discussions concerning the remit, permitted areas of work and regis- 


\begin{tabular}{l} 
Table 1 Overview of project \\
\begin{tabular}{l|l|l|l|l}
\hline Sphere of use of progress file & 1 0ct 1998 & 2 Feb 1999 & 3 Apr 1999 & 4 Aug 2000 \\
\hline Initial training/education & $\begin{array}{l}\text { Consultations with } \\
\text { students and trainers }\end{array}$ & $\begin{array}{l}\text { Development of } \\
\text { prototype } \\
\text { progress file }\end{array}$ & $\begin{array}{l}\text { Trial/appraisal by } \\
\text { students and } \\
\text { trainers }\end{array}$ & $\begin{array}{l}\text { Production of } \\
\text { progress file }\end{array}$ \\
Employment/practice & $\begin{array}{l}{ }^{*} \text { Consultations with } \\
\text { employees (DTs) and } \\
\text { employers/managers } \\
\text { (dentists) }\end{array}$ & $\begin{array}{l}{ }^{*} \text { Trial/appraisal by } \\
\text { DTs and dentists }\end{array}$ & & \\
\hline
\end{tabular} \\
\hline *Aspects of the project reported in this paper.
\end{tabular}

* Aspects of the project reported in this paper.

\section{Trial, evaluation and appraisal}

The prototype PF was sent to 28 therapists for trialling and to 15 dentists for appraisal. The therapists comprised 13 from the consultations, who had indicated willingness to participate, plus 15 newly qualified therapists (approximately half of all dental therapists qualifying in 1999). All dentists had participated in the consultations; only one worked with a therapist involved in the trial. Therapists were asked to use part four of the file, following directions included in it and involving their employers in a supportive role if possible and desired. Dentists were asked to examine the file to provide constructive criticism. After six months, a questionnaire comprising categorical and open-ended questions was sent to therapists to elicit whether the PF had been used, their opinion on its usefulness, whether employers had been involved, difficulties encountered and suggestions for improvement. At the same time, dentists were sent a questionnaire to elicit their opinion on the PF and suggestions for improvement. Seventeen questionnaires were returned by therapists (61\%); ten were returned by dentists (67\%). Response frequencies were calculated and open-ended responses were contentanalysed as before.

\section{Consultations}

A small opportunistic sample of 15 dentists and 32 therapists participated in the consultations. The dentists were drawn from general practice, the community service and PDS pilots and included principals/partners, associates and salaried dentists. Seventeen of the therapists were practicing as therapists, 15 were employed as hygienists. They were drawn from hospital and community services, PDS pilots and, in the case of some of the hygienists, from general practice. All dentists were interviewed. Half the therapists were interviewed and half were sent a questionnaire. The decision to interview or to send a questionnaire was based on location. Both methods explored attitudes and views towards PFs, lifelong learning, CPD, recording achievement, development of the profession and dental therapists achieving their potential. The questionnaire contained Likert scale statements, categorical and open-ended questions. Interviews were tape-recorded. Thirteen completed questionnaires were returned (87\%). Response frequencies were calculated and interview transcripts and open-ended questionnaire responses were content-analysed ${ }^{11}$ (ie categorized to enable themes and issues to be discerned). The results, together with those obtained from therapy students and trainers, ${ }^{9}$ informed the development of the prototype PF (Table 2).

\section{FINDINGS}

\section{Pre-trial consultations}

A number of factors to take into account in development and implementation of the PF emerged from the consultations:

- Dentists, particularly in general practice, were unfamiliar with the training and working remit of dental therapists.

- Some dentists were unfamiliar with, or uncertain about, supporting/supervising employees in areas such as reflective practice and recording achievement.

- Most therapists felt they would benefit from being more reflective.

- Some therapists reported difficulties in identifying and recording their achievements since qualifying.

- Therapists undertook a variety of CPD activities, ranging from formal courses and conferences to in-surgery training and private study, but not all CPD activities were evaluated or recorded.

- Most therapists felt they would benefit from more CPD and from a formal system or framework for managing it.

- Most therapists had some form of CPD provision made by their employers, ranging from general support and verbal encouragement to peer review, staff appraisal, time off and funding for courses; provision was not always perceived to be adequate. 
Table 3 Potential uses for progress files as identified by dental therapists and dentists

\begin{tabular}{|c|c|c|}
\hline \multirow[t]{2}{*}{ Potential use for PF } & \multicolumn{2}{|l|}{ Typifying quotes } \\
\hline & Therapists & Dentists \\
\hline $\begin{array}{l}\text { Facilitating application } \\
\text { for employment/selection }\end{array}$ & $\begin{array}{l}\text { 'Would like it for interview to demonstrate range of experience.' } \\
\text { 'Might be useful to an employer who was looking for experience } \\
\text { in a particular area of relevance to their practice.' }\end{array}$ & $\begin{array}{l}\text { 'May be a good discussion point for interview.' } \\
\text { 'The dentist might wish to know how a therapist fits into the } \\
\text { practice from the point of view of her experience gained, to } \\
\text { fit in with a particular valued specialism.' }\end{array}$ \\
\hline $\begin{array}{l}\text { Induction of newly- } \\
\text { qualified therapists }\end{array}$ & $\begin{array}{l}\text { 'Might stop you being thrown in at the deep end without } \\
\text { appropriate support in a first post.' }\end{array}$ & $\begin{array}{l}\text { 'We do a lot of this already-it is a good way to support } \\
\text { a new therapist.' } \\
\text { 'It's a good thing to have a plan-especially in the first year of } \\
\text { a dental therapist's working life.' }\end{array}$ \\
\hline Promoting CPD & 'It might stimulate the process of CPD if it doesn't come naturally'. & \\
\hline $\begin{array}{l}\text { Structuring, informing } \\
\text { and organizing self-audit/ } \\
\text { staff appraisal }\end{array}$ & $\begin{array}{l}\text { 'The PF could provide guidelines for therapists and employers' } \\
\text { 'Useful as a record of what you and your employer have agreed to do.' }\end{array}$ & $\begin{array}{l}\text { 'There should be a checklist of tasks... a clinical } \\
\text { checklist that can be done between the dentist and } \\
\text { dental therapist.' }\end{array}$ \\
\hline $\begin{array}{l}\text { Facilitating assessment/ } \\
\text { discussion of performance }\end{array}$ & $\begin{array}{l}\text { 'The dentist's got to have the opportunity to assess your work... without } \\
\text { the therapist feeling she's being 'checked up on' - if it's a formal situation } \\
\text { you're automatically going to accept it.' }\end{array}$ & $\begin{array}{l}\text { 'You don't get to know the quality of a novice until you } \\
\text { are in there for six months - there needs to be this } \\
\text { further assessment after a period with the dentist.' }\end{array}$ \\
\hline $\begin{array}{l}\text { Enhancing working } \\
\text { relationships }\end{array}$ & $\begin{array}{l}\text { 'It would give you the chance to develop a working relationship - so you're } \\
\text { not going to feel awkward about saying 'I need help.' }\end{array}$ & $\begin{array}{l}\text { 'This would cement the relationship between dental } \\
\text { therapist and dentist.' } \\
\text { 'It is revealing what type of person I am employing.' }\end{array}$ \\
\hline
\end{tabular}

Participants in the consultations identified several potential uses for a PF (Table 3). They also anticipated barriers to using a PF (Table 4). Quotes in these tables are selected, typifying quotes, reported irrespective of the numbers offering each opinion. Factors that might improve use of a PF were also suggested by dentists and therapists, including:

- Minimize the amount of time employers need to give to PFs.

- Make PFs part of formal requirements.

- Emphasize that PFs can benefit the whole practice, by having a motivated, up to date and monitored work force.

- Remunerate dentists for time spent on staff development and appraisal using the PF.

- Train dentists in supervising the CPD of their staff.

- Introduce across the team and as early in training as possible.

\section{Evaluation of PF by therapists}

Most respondents agreed that the PF was 'a useful learning tool for therapists at work'. Their comments reflected this opinion:

'It has been a very useful way of reflecting and assessing one's own capabilities, providing motivation and direction to extend and develop one's skills.'

'A good tool for recording personal and professional development in order for the employed therapist to continue as lifelong learner.'

\begin{tabular}{|c|c|c|}
\hline \multirow[t]{2}{*}{ Barriers } & \multicolumn{2}{|l|}{ Typifying quotes } \\
\hline & Therapists & Dentists \\
\hline $\begin{array}{l}\text { Time/effort required } \\
\text { to use }\end{array}$ & $\begin{array}{l}\text { 'I am concerned about the amount of time } \\
\text { and paperwork that might be involved in } \\
\text { developing a PF. }\end{array}$ & $\begin{array}{l}\text { 'The dentist runs a business and may } \\
\text { not have the time.' } \\
\text { 'In general practice, it may be difficult } \\
\text { to give that level of support.' }\end{array}$ \\
\hline Not needed & & $\begin{array}{l}\text { 'The diploma qualifies the dental } \\
\text { therapist to act appropriately - I } \\
\text { don'tneed proof.' }\end{array}$ \\
\hline Might be too revealing & $\begin{array}{l}\text { 'When you go for a job you only want } \\
\text { to be putting your positive points } \\
\text { forward.' } \\
\text { 'Employers don't want the nitty-gritty.' }\end{array}$ & $\begin{array}{l}\text { 'It might be counter-productive to be } \\
\text { too self-critical... you may be } \\
\text { perceived as falling apart too easily.' } \\
\text { 'OK for therapist's own reflection but } \\
\text { not for discussion.' }\end{array}$ \\
\hline $\begin{array}{l}\text { Persuading employers to } \\
\text { become involved in the } \\
\text { CPD aspect }\end{array}$ & $\begin{array}{l}\text { 'As long as you can do the job they're } \\
\text { not interested in what you want to do' }\end{array}$ & $\begin{array}{l}\text { 'Dentists won't want to take on that } \\
\text { role - why should they?' } \\
\text { 'My interest would be marginal.' } \\
\text { 'It's hard work.' }\end{array}$ \\
\hline
\end{tabular}

However some therapists felt that the PF still:

'Needs to be smaller and less time consuming.'

The therapists who trialled the PF had completed variously: the personal record (in part three) and some of the activities (eg an 'action plan' and 'checklist of clinical activities') and CPD records in part four. Most agreed that the PF helped them to 'record achievements', 'reflect on clinical practice and professional development' and 'identify ways to improve clinical practice and professional development'.

Approximately half had had their employer's involvement in using the PF. Specifically, employers had supported therapists in completing the activities in the CPD section, for example by:

'Discussing new ideas for future prospects.'

A variety of reasons were given for non-involvement of employers including:

'I see this as a personal record.'

'He has not thought it necessary.'

\section{Appraisal of PF by dentists}

Most respondents agreed that the PF was 'a useful tool for encouraging lifelong learning', 'provided information that was helpful for employers' and 'might facilitate the selection of the most suitable employee'. A typical comment was:

'PF is helpful for the student at an early stage of their career ie what their 
concerns are, what they have learned, experienced and it provides a good backbone for professional development following qualification.'

Some dentists identified problems remaining with the $\mathrm{PF}$ :

'Too long-winded for an employer to read.

'I think that this file is very useful for newly-qualified and training therapists. Once they have been qualified for about a year I doubt that the momentum would be maintained for continued use.'

In relation to employers' involvement with the CPD section of the PF, almost all saw it as their role to review progress, provide encouragement and make suggestions regarding their employees' professional development, for example through:

'Support, talking, listening to problems, suggesting solutions.'

'Try to improve in weak areas, suggest attendance at courses.'

Around half also felt it was their job to provide professional development activities in-house and to assist employees in drawing up action plans. However, few saw it as their responsibility to finance employees' CPD activities.

Overall, many of the expectations and impressions regarding the PF expressed during the consultations were borne out by participants in the evaluation and appraisal.

\section{DISCUSSION}

In what follows the terms 'employer' and 'dentist' are used interchangeably to signify the leader of the dental team although in hospital and community dental services the dentist is not him or herself 'the employer'. The discussion refers to dental therapists but most of it is also pertinent to other members of the dental team.

The conduct of this particular aspect of the development of a PF for dental therapists involved only a small number of individuals in an attempt to expedite development. They may not be representative of working dental therapists or even their employers. However, a recent evaluation of promoting change in SHO training in Scotland confirmed similar outcomes to this study in terms of usefulness, knowledge of how to use, and perceived benefits of a logbook/portfolio diary. ${ }^{12}$

\section{Supporting employees' professional development}

The evaluation and appraisal suggest that a PF may be a useful tool for dental therapists, together with dentist/employers, to further personal and professional development.
As with all professions, the future success of dental therapy depends on the quality of education and professional development. This is even more important where a profession is given new responsibilities. ${ }^{7}$ The evaluation shows that a PF could encourage newly qualified therapists and others to review strengths and weaknesses, and improve skills and competencies in identified areas.

Many facets of the PF (eg checklist of clinical skills, action planning) draw attention to the need for input (eg advice, verification of records) from the team leader. The engagement of the dentist in PF use would be particularly important in the absence of any other formal vocational training or CPD for dental therapists. However, the data show that such engagement may be problematic, at least without training, payment or other ways (see below) of rewarding employers for time spent on this task.

\section{The value of a progress file for the practice}

Many aspects of the PFs, it appears, are already familiar to employers (eg action plan, self-audit, appraisal). Community dentists, in particular, are already widely engaged in helping team members to realize potential, supporting skills development through staff appraisal. For general practice, training needs analyses are now recommended to help ensure the quality objectives of the organization. ${ }^{13}$ A PF could provide a forum for discussion of these issues, enhancing communication within the dental team and contributing to raising standards of care by encouraging CPD.

Once general dental practitioners (GDPs) are permitted to employ dental therapists, a PF could aid recruitment, providing information about the remit of therapists, as well as on an individual candidate's background and achievements. It might help to ensure employment of the best person, particularly where a specific skill is sought for the practice (eg special needs).

\section{Monitoring skills and competencies}

A PF could facilitate the monitoring of skills and competencies, and make it easier for the dentist to 'step in' where improvement is needed. It could provide a framework and protocol, acceptable to all, that the employer could use for tackling problems of daily practice, especially those of a 'delicate' nature (eg team dynamics, slipping standards) in a sensitive manner, reducing the risk of damaging working relationships.

\section{Costs to employers}

Whilst dentists in this study (particularly GDPs) acknowledged the benefits of using a PF, they also considered the costs. As data suggests, many may be reluctant to commit themselves to engaging with a PF due to perceived lack of time, expertise and rewards. Typically, they held that giving 'support' to employees was acceptable but any greater degree of involvement in their professional development would happen only if tangibly rewarded.

\section{Rewarding employers}

From the literature of decision-making, social cognition models ${ }^{14}$ suggest that for people to engage in action they must be convinced of the benefit of that action - that is, the action must be perceived as cost-effective. Accordingly we might ask: what are the benefits to employers themselves of supporting employees' use of a PF - over and above the benefits to the team and practice as a whole?

One possible answer involves recognizing that the support an employer gives to an employee using a PF contributes to the employer's own professional development. This ought to be acknowledged. Dentists should be able to demonstrate (perhaps by compiling their own PF) the gains they have made (eg in supervisory or team development skills) through time spent working on PF activities with staff - and this should count towards their own CPD requirement.

\section{Quality assurance and accountability}

Used by the whole team as an instrument to encourage CPD and make learning explicit, a PF has the potential to pull together the many strands of quality assurance requirements for its stakeholders. It could become a symbol of accountability, providing the evidence dentists and PCDs need to lay claim to time spent on CPD and potentially being an important feature of professional reregistration. If PFs were to be used in this way, it would be vital to identify which parts were to provide evidence and be open to scrutiny, and which (if any) were for private reflection.

\section{CONCLUSION}

The commitment by the Government and other associated bodies to make the NHS a quality service requires change, accountability and redistribution of professional responsibilities within the dental team. Modern healthcare also requires continuous updating of personnel. PFs have the potential to play an important role in these processes. They can act as ambassadors for the dental therapy profession; provide a framework for engaging dentists in the professional development of their employees, at the same time as contributing to their own CPD requirement, ultimately 
being tools usable by the entire team. But for a PF to be a viable option for dental practice, the dentist and others need to be confident that their efforts, in this regard, are rewarded.

The authors thank all who participated in the study. The Government Office for London, Higher Education Regional Development Fund Project 98-00/03, funded the project.

1. Committee for Vocational Training. Professiona development portfolio for vocational dental practitioners.

2. Baker $A$, Magennis $P$, Patel $M$, Roger S.
Maxillofacial trainee logbook. London: Royal College of Surgeons, 1997.

3. National Committee of Inquiry into Higher Education. Higher education in the learning society. London: HMSO, 1997.

4. Quality Assurance Agency for Higher Education. Guidelines for HE progress files. Gloucester: QAA, 2001.

5. General Dental Council. The first five years: the undergraduate dental curriculum. London: GDC, 1997.

6. General Dental Council. Lifelong learning: taking dentistry forward. London: GDC, 2000.

7. General Dental Council Dental Auxiliaries Review Group. Professionals complementary to dentistry: a consultation paper. London: GDC, 1998.

8. www.mds.qmw.ac.uk/eqapublic/innovations
9. Pee B, Woodman T, Fry H, Davenport E S. Practicebased learning: views on the development of a reflective learning tool. Med Educ 2000; 34: 754 761.

10. Fry H, Davenport ES, Woodman T, Pee B. Developing progress files: a case study. Teaching in Higher Education 2002: 7: 99-113.

11. Burns R. Introduction to research methods. London: Sage Publications, 2000 pp.432-435.

12. Clark J D, Thomas M, Robertson L. A novel approach to promoting change in $\mathrm{SHO}$ training in a dental teaching hospital. Br Dent J 2002; 193: 167-171.

13. Grace M. Training needs analysis. Br Dent J 2001; 190: 524-526.

14. Ajzen I. The theory of planned behaviour. Organizational Behaviour and Human Decision Processes 1991; 50: 179-211. 